\title{
Current concepts in management of gestational diabetes mellitus
}

\author{
Kalinga Nanayakkara ${ }^{1}$ \\ Sri Lanka Journal of Obstetrics and Gynaecology 2010; 32: 99-105
}

\section{Introduction}

Gestational diabetes mellitus (GDM) defined as "glucose intolerance of any degree with onset or first recognition during pregnancy", results when there is a reduction in the pancreatic $\beta$-cell effect of $67 \%$ or more when compared with normal pregnant women ${ }^{1}$. It generally occurs in 3-10\% of pregnant women ${ }^{2}$, but its prevalence may range from 1 to $14 \%$ of pregnancies, depending on the population studied ${ }^{3}$. GDM represents $90 \%$ of all cases of diabetes mellitus that are diagnosed during pregnancy. Tragically, its prevalence in pregnancy had doubled in the last 8 years, a $12 \%$ increase per year ${ }^{4}$.

\section{Pre-conceptional counselling}

Expectant mothers must be advised to maintain a fasting plasma glucose between $80-90 \mathrm{mg} / \mathrm{dl}$, postprandial plasma glucose between $110-120 \mathrm{mg} /$ $\mathrm{dl}$ and $\mathrm{HbA} 1 \mathrm{C}$ below $6.5 \%, 3$ months before conception and to take a prenatal vitamin containing at least 5 $\mathrm{mg} / \mathrm{d}$ folic acid. This is in keeping in mind the $9-14 \%$ miscarriage rate in women with preexisting diabetes mellitus and the rates for birth defects reported between 5.1 and $9.8 \% 5,6$ even with optimal control, as against $1-2 \%$ for the general population. In a mother with a previous pregnancy complicated by GDM the risk for GDM in the second pregnancy is $41.3 \%$ when compared to $4.2 \%$ in normoglycaemic women (OR, 13.2; $95 \%$ confidence interval [CI], 12.0-14.6) $)^{7}$. Increased incidence of preeclampsia, $12 \%$ as compared to $8 \%$ for the nondiabetic and macrosomia ${ }^{8}$ warrants monitoring the blood pressure and advice on avoiding obesity. It is also prudent to consider an ophthalmologic evaluation.

\section{Screening}

Antenatal screening for diabetes involves universally testing all pregnant mothers by a 50 -g oral glucose challenge test [GCT] and performing a diagnostic OGTT on that subset of women exceeding the glucose threshold value at 1-hour of $>140 \mathrm{mg} / \mathrm{dl}$ (7.8 mmol/l), which identifies $80 \%$ of women with GDM, or $>130 \mathrm{mg} / \mathrm{dl}(7.2 \mathrm{mmol} / \mathrm{l})$ which identifies

\footnotetext{
${ }^{1}$ Consultant Obstetrician and Gynaecologist, Kandy, Sri Lanka

E-mail: kalingananayakkara@yahoo.com
}

$90 \%{ }^{9}$. Alternatively selective screening could be performed on the following subset of women with the definitive criteria listed below:

1. Maternal age older than 35 years

2. Previous infant weighing more than $3500 \mathrm{~g}$

3. Glycosuria in second urine sample

4. Previous unexplained fetal demise

5. Previous pregnancy with GDM

6. Strong immediate family history of type 2 diabetes mellitus (T2DM ) or GDM

7. Obesity (>90 kg)

8. Fasting plasma glucose (FPG) value greater than $140 \mathrm{mg} / \mathrm{dl}(7.8 \mathrm{mmol} / \mathrm{L})$ or random glucose value greater than $200 \mathrm{mg} / \mathrm{dl}(11.1 \mathrm{mmol} / \mathrm{L})$

\section{Diagnosis}

Over the years diabetes has been diagnosed in pregnancy using the well-documented WHO criteria as listed in Table $1^{10}$.

Table 1. 2006 WHO diabetes criteria

\begin{tabular}{lll}
\hline Condition & $\begin{array}{l}\text { Fasting } \\
\text { glucose } \\
\mathrm{mmol} / \mathrm{l}(\mathrm{mg} / \mathrm{dl})\end{array}$ & $\begin{array}{l}2 \text { hour } \\
\text { glucose } \\
\mathrm{mmol} / \mathrm{l}(\mathrm{mg} / \mathrm{dl})\end{array}$ \\
\hline Normal & $<6.1(<110)$ & $<7.8(<140)$ \\
\hline $\begin{array}{l}\text { Diabetes } \\
\text { mellitus }\end{array}$ & $\geq 7.0(\geq 126)$ & $\geq 11.1(\geq 200)$ \\
\hline
\end{tabular}

Hyperglycaemia and adverse pregnancy outcome (HAPO) study

The HAPO study sought to clarify the association between multiple adverse outcomes of pregnancy and degrees of hyperglycemia less severe than those diagnostic of diabetes ${ }^{11}$. Study consisted of 25,000 women in 9 countries. Increasing glucose concentration less severe than diabetes was associated with fetal macrosomia. It is also suggested that fluxes of glucose levels other than fasting or postprandial states were related to excessive fetal growth. There were also strong associations between maternal glucose levels with preeclampsia (ORs 1.40-1.57), shoulder dystocia and/or birth injury (1.30-1.43). 
The International Association of Diabetes and Pregnancy Study Group (IADPSG) and the new diagnostic criteria for GDM

The International Association of Diabetes and Pregnancy Study Group (IADPSG) was formed in 1998 as an umbrella organization to study and focus on diabetes and pregnancy. IADPSG which reviewed the data of the HAPO study made the following recommendations for new diagnostic criteria for GDM, as listed in Table $2^{12}$. The average glucose values were at which odds for birth weight $>90$ th percentile, cord blood C-peptide $>90$ th percentile, and percent body fat $>90$ th percentile reached 1.75 times the estimated odds of these outcomes.

Table 2

\begin{tabular}{ll}
\hline $\begin{array}{l}\text { Maternal glucose } \\
\text { following } 75 g \text { GTT }\end{array}$ & $\begin{array}{l}\text { Proposed diagnostic } \\
\text { threshold for GDM }\end{array}$ \\
\hline Fasting plasma glucose & $92 \mathrm{mg} / \mathrm{dl}(5.1 \mathrm{mmol} / \mathrm{L})$ \\
1 hour plasma glucose & $180 \mathrm{mg} / \mathrm{dl}(10 \mathrm{mmol} / \mathrm{L})$ \\
2 hour plasma glucose & $153 \mathrm{mg} / \mathrm{dl}(8.5 \mathrm{mmol} / \mathrm{L})$ \\
\hline
\end{tabular}

The diagnosis is made easier in that only 1 of these cut-offs (FPG, 1-hour OGTT, or 2-hour OGTT) must be met or exceeded to diagnose GDM.

\section{Pre-diabetes}

Impaired fasting glucose (IFG) is detected when the FPG level is $\geq 100 \mathrm{mg} / \mathrm{dl}(5.6 \mathrm{mmol} / \mathrm{l})$ but $<126$ $\mathrm{mg} / \mathrm{dl}(7.0 \mathrm{mmol} / \mathrm{l})$ and impaired glucose tolerance (IGT) when the 2-hour $75 \mathrm{~g}$ OGTT value is $\geq 140 \mathrm{mg} /$ dl $(7.8 \mathrm{mmol} / \mathrm{l})$ but $<200 \mathrm{mg} / \mathrm{dl}(11.1 \mathrm{mmol} / \mathrm{l})$. While not meeting criteria for diabetes they are however associated with the metabolic syndrome, which includes obesity, dyslipidemia of the high-triglyceride and/or low-HDL type, and hypertension. Interestingly $19 \%$ of people over the age of 20 years, the group which includes childbearing women, have prediabetes ${ }^{13}$, which has been listed as "America's largest healthcare epidemic ${ }^{114}$.

\section{Management}

\section{(a) Dietary regulation}

The foundation of treatment for all patients is a diet consisting carbohydrates lower than $40 \%$. However, $30-50 \%$ of women with GDM require pharmacological therapy when diet alone fails to reduce glucose levels ${ }^{15}$. Pharmacological therapy is commenced by some when the FPG is $\geq 95 \mathrm{mg} / \mathrm{dl}$ and by others when it is $\geq 105 \mathrm{mg} / \mathrm{dl}^{16}$. However, all authorities agree that drug therapy should be initiated when 2-hour postprandial glucose levels are $\geq 120 \mathrm{mg} /$ $\mathrm{dl}$ or 1 -hour levels are $\geq 140 \mathrm{mg} / \mathrm{dl}^{17}$. Patients with a fasting plasma glucose $<105 \mathrm{mg} / \mathrm{dl}$ can be selected for a 'trial of diet therapy' for a 2 to 4 week period ${ }^{18}$. However, when GDM is diagnosed after 30-33 weeks' gestation, pharmacological intervention is recommended as there is limited time available to influence the desired level of control.

\section{(b) Medication}

Oral anti-diabetic agents (OAA)

The basis for the long-standing apprehension for use of OAAs during pregnancy stems from the fact that first-generation sulfonylureas crossed the placenta readily $(21.5 \%$ for tolbutamide, $11 \%$ for chlorpropamide). The second-generation sulfonylureas crossed however to a much lesser extent, $6.6 \%$ for glipizide and $3.9 \%$ for glibenclamide ${ }^{19}$. No glibenclamide was detected in the cord blood ${ }^{20}$. Possible reasons for the minimal transfer of glibenclamide include its high protein binding $(99.8 \%)$, short elimination half-life $(10 \mathrm{~h})$ and the placenta actively pumping glibenclamide back into the maternal circulation by adenosine-triphosphatebinding cassette transporters ${ }^{21}$. Data from studies in rats and rabbits revealed that neither glibenclamide nor glipizide was teratogenic, even when given in large doses ${ }^{22}$. Also no significant teratogenicity was observed in rats fed with metformin four times the maximum recommended human dose (MRHD) and with rosiglitazone 20-75 times the MRHD ${ }^{23}$.

\section{Glibenclamide}

Langer et al conducted a large randomized controlled trial using glibenclamide $2.5-20 \mathrm{mg}$ / day (mean 9) and compared it with insulin in 404 women with gestational diabetes. No significant difference was found in glycaemic control or neonatal outcomes ${ }^{24}$. Failure with glibenclamide is predicted if fasting glucose levels are greater than $110 \mathrm{mg} / 100 \mathrm{ml}^{25}$.

\section{Biguanides}

Metformin has been shown to pass freely across the placenta. Two in vivo studies in women taking metformin throughout pregnancy, $850 \mathrm{mg}$ twice daily in 15 women $^{36}$ and $2000 \mathrm{mg} /$ day in 8 women respectively, showed that the fetus is exposed to concentrations as high as those seen in the mother ${ }^{26,27}$. One recent study examining the use of metformin throughout pregnancy in 109 women with PCOS found normal growth and motor development in infants (126 live births) followed up to 18 months $^{28}$. In a meta-analysis evaluating the safety of sulfonylureas and biguanides administered in the first trimester, which included 10 studies on 471 exposed women, no significant difference was found in the rate of major malformations or neonatal deaths ${ }^{29}$. 


\section{Thiazolidinediones}

Rosiglitazone and pioglitazone freely cross the placenta $^{30}$. Because there is no clinical study to date reporting on the use of thiazolidinediones in pregnancy, these agents should not be prescribed.

\section{Insulin therapy}

Insulin has long been the mainstay of pharmacological treatment for women with gestational diabetes. Regular check-ups are by plasma sugar estimations. The Fifth International Workshop Conference on Gestational Diabetes ${ }^{31}$ currently recommends the following:

o Fasting plasma glucose 90-99 mg/dL (5.0-5.5 $\mathrm{mmol} / \mathrm{L}$ ) and

o One-hour postprandial plasma glucose less than $140 \mathrm{mg} / \mathrm{dL}(7.8 \mathrm{mmol} / \mathrm{L})$ or

o Two-hour postprandial plasma glucose less than $120-127 \mathrm{mg} / \mathrm{dL}(6.7-7.1 \mathrm{mmol} / \mathrm{L})$.

\section{Insulin pump}

The effectiveness of continuous subcutaneous insulin infusion in pregnancy is well established . Hieronimus et al compared outcome of 33 pregnant women managed with insulin pump to 23 receiving multiple injections, reporting similar HbA1c levels, macrosomia rates, and caesarean rates ${ }^{32}$. Lapolla et al reported a small cohort of 25 women treated with insulin pump in pregnancy compared to conventional insulin treatment $(n=68)$ and found no differences in glycaemic control or perinatal outcome ${ }^{33}$.

\section{(c) Fetal monitoring}

Periodic fetal biophysical testing

In patients with poor glycaemic control, intrauterine growth restriction or significant hypertension, formal biophysical testing involving fetal heart rate testing, fetal movement assessment, ultrasonographic biophysical scoring, and fetal umbilical Doppler studies could be commenced as early as 28 weeks. In patients who are at lower risk, most centres begin formal fetal testing by 34 weeks. Fetal movement counting is performed in all pregnancies from 28 weeks onward.

\section{Imaging studies}

Apart from laboratory studies the following imaging studies are recommended.

- First trimester

o Sonogram (crown-rump length) for dating and viability and for nuchal translucency.
- Second trimester

o Detailed anatomy sonogram at 18-20 weeks.

o Fetal echocardiogram if $\mathrm{HbA1C}$ value was elevated in first trimester.

\section{- Third trimester}

o Growth sonogram to assess fetal size every 4-6 weeks from 26-36 weeks in women with overt preexisting diabetes.

o Growth sonogram for fetal size at least once at 36-37 weeks for women with gestational diabetes mellitus (consider performing this study more frequently if macrosomia is suggested).

Assessing fetal growth

Monitoring fetal growth continues to be a challenging and an imprecise process as the accuracy is still only within $\pm 15 \%$. Fetuses predicted to weigh between 4000 grams and 4500 grams based on ultrasonographic findings actually weigh that much only in $50 \%$ of the time. In 1992, Bernstein and Catalano reported that significant correlation existed between the degree of error in the ultrasonogram-based estimation of fetal weight and the percent of body fat on the fetus $(\mathrm{r}=0.28, \mathrm{P}<.05)^{34}$. The accelerated growth of the abdominal circumference begins to rise significantly above normal after 24 weeks.

\section{Intra partum management}

Timing and route of delivery

An optimal time for delivery of most diabetic pregnancies is typically on or after the 39th week. In patients with gestational diabetes mellitus and good glycaemic control, continued fetal testing and expectant management can be considered until 41 weeks of gestation. However, after 40 or more weeks, the benefits of continued conservative management are likely to be less than the danger of fetal compromise.

\section{Avoiding shoulder dystocia}

While shoulder dystocia occurs in $0.3-0.5 \%$ of vaginal deliveries among healthy pregnant women, the incidence is 2- to 4-fold higher in women with diabetes. With strict glycaemic control, the birth injury rate has been shown to be only slightly higher than controls $(3.2 \text { vs } 2.5 \%)^{2}$.

\section{Post partum management}

\section{Post-natal advice}

Glucose tolerance tests are performed 6 weeks post-partum to determine whether it was GDM or a new diagnosis of type 2 diabetes. Close follow-up of 
women with previous GDM, is possible only in 50\% in the United States ${ }^{35}$, with the promotion of a combination of breastfeeding, lifestyle changes with increased physical activity, weight loss and a healthy diet, to significantly reduce the maternal risk for type 2 diabetes mellitus (T2DM).

\section{Management of the neonate}

Tight glycaemic control has dramatically reduced the incidence of neonatal respiratory distress syndrome (RDS) from $31 \%$ to $3 \%^{36}$ and neonatal hypoglycaemia ${ }^{37}$. Neonatal hypocalcaemia and polycythemia too are recognized complications. Postnatal hyperbilirubinaemia occurs in approximately $25 \%$ of infants of diabetic mothers, a rate approximately double that in a healthy population.

\section{Use of oral antidiabetic agents while breast-feeding}

First-generation sulfonylureas, tolbutamide and chlorpropamide, have been found to cross into breast milk ${ }^{26}$. Both glibenclamide and glipizide appeared to be compatible with breast-feeding ${ }^{38}$. No glibenclamide was found in milk samples ${ }^{39}$. Metformin is excreted into breast milk at very low levels ${ }^{40}$ and there was no significant difference in weight, height, or motor-social development of infants at 3 and 6 months of age $\mathrm{a}^{41}$. There have been no reports to date of studies evaluating the passage of thiazolidinediones into breast milk.

\section{Long term follow up}

In a new meta-analysis of 20 cohort studies involving 675,455 women and 10,859 cases of T2DM, Bellamy and colleagues reported that women with previous GDM have at least a 7.5-times increased risk of developing T2DM in the future, compared with those with normoglycaemic pregnancy and the relative risk of 4.69 of developing T2DM within 5 years of a pregnancy doubling to $9.34^{42}$.

\section{Risk of cardiovascular disease}

Relatively young women, just 2 years after a GDM pregnancy, have been observed to have increased carotid artery intima-media thickening and are at risk of early onset of subclinical atherosclerosis ${ }^{43,44}$. Shah et al calculated the hazard ratio for CVD events in women with past GDM to be 1.71 and postulated that T2DM and CVD probably develop in parallel in this group of patients ${ }^{45}$.

Prevention of T2DM and cardio-vascular disease (CVD) in women with GDM

The American Diabetes Association recommends the following protocol for the prevention of T2DM and CVD in women with GDM ${ }^{46}$

1. OGTT 6 weeks post-partum to detect either established T2DM or impaired glucose intolerance.

2. Annual OGTT for those with impaired fasting glucose or impaired glucose intolerance.

3. Regular OGTT after one year even when the postpartum results are normal.

4. Abdominal circumferences, blood pressure and lipid profile to be investigated in addition to the OGTT.

\section{Childhood obesity}

The degree of adiposity at birth, independent from the weight at birth, calculated from the birth weight, length, and flank skin fold thickness according to the equation given by Catalano et $a l^{47}$, expresses the possibility that a newborn may have relatively more fat than one born with a heavier birth weight ${ }^{48}$.

\section{Childhood metabolic syndrome}

By age 10-16 years, offspring of diabetic pregnancy have a $19.3 \%$ rate of impaired glucose intolerance ${ }^{49}$. A growing body of literature now supports a relationship between intrauterine exposure to maternal hyperglycaemia and risk of childhood obesity and metabolic syndrome later in life ${ }^{50,51}$.

\section{(d) Recommendations for clinical practice}

Recommendations of the American Diabetes Association (ADA) for the diagnosis of GDM in view of the IADPSG proposals (February 27, 2010) ${ }^{52}$

A. Women with high risk characteristics for GDM (mentioned earlier) should undergo an OGTT testing as soon as feasible and re-tested between 24 and 28 weeks if found to be normal

B. All antenatal mothers to have their fasting plasma glucose (FPG) checked at booking visit.

(i) Fasting plasma glucose $\geq 7.0 \mathrm{mmol} / 1$ (126 $\mathrm{mg} / \mathrm{dl}$ ) indicated overt diabetes, therefore treat and follow-up as for pre-existing diabetes

(ii) Fasting plasma glucose $\geq 5.1 \mathrm{mmol} / 1$ (92 mg/ dl) but $<7.0 \mathrm{mmol} / 1(126 \mathrm{mg} / \mathrm{dl})$, test with a 75-g OGTT to diagnose GDM

(iii) Fasting plasma glucose $<5.1 \mathrm{mmol} / 1$ (92 mg/ dl), test for GDM from 24 to 28 weeks' gestation with a 75-g OGTT

C. A 2-h 75-g OGTT to be performed on all women not previously found to have overt diabetes or GDM during testing earlier in this pregnancy. 
(1) Overt diabetes if fasting plasma glucose $\geq 7.0$ $\mathrm{mmol} / \mathrm{l}(126 \mathrm{mg} / \mathrm{dl})$.

(2) GDM if one or more values equals or exceeds thresholds indicated in Table 2.

(3) Normal if all values on OGTT less than thresholds indicated in Table 2.

The cost-effectiveness of the above schedule has been hotly debated and the National Institute for Health and Clinical Excellence (UK) have concluded that "screening, diagnosis, and treatment of gestational diabetes is cost-effective ${ }^{1153}$.

\section{(e) Recommendations for future research}

The same risk factors appear to govern both GDM and T2DM, suggesting a common genetic background for both ${ }^{54}$. In accordance with the suggestion of a common genetic background it is hypothesized that women with previous gestational diabetes (pGDM) and GDM display some alleles associated with a high risk of $\mathrm{T} 2 \mathrm{DM}^{55,56}$

Post-natal medication for normotolerant women with previous GDM

Buchanan et al, in the Triglitazone in the Prevention of Diabetes (TRIPOD) study ${ }^{57}$ and women with pGDM enrolled in the Diabetes Prevention Programme where normotolerant postpartum women were treated with metformin, have reported a $55 \%$ and $50 \%$ respective risk reduction in progression to T2DM. However, it should be noted that these medications are not currently approved for use in T2DM prevention and that additional studies are needed to evaluate the cost-effectiveness of these preventive measures for both T2DM and CVD.

\section{Conclusions}

Diabetes is alarmingly spreading around the globe in 'pandemic' proportions. The new diagnostic criteria recommended by IADPSG identified 16.1\% of the pregnant population as having GDM . This with $1.7 \%$ of pregnant women with overt diabetes discovered for the first time in pregnancy, raises the total incidence of gestational diabetes in pregnant women to $17.8 \%$. Interestingly this is close to the $19 \%$ of people over the age of 20, the group which includes childbearing women, who are found to have prediabetes $^{58}$. Obesity and a family history of T2DM represented the most important risk factors for the development of $\mathrm{GDM}^{45}$.

A meta-analysis evaluating the safety of metformin, glibenclamide, and glipizide indicates their safety even when administered in the first trimester ${ }^{29}$ and they appear to be compatible with breast-feeding. However, their use in normotolerant women postpartum, for T2DM prevention, is not currently approved.

The Fifth International Workshop on Gestational Diabetes and the North American Diabetes in Pregnancy Study Group have endorsed the use of glibenclamide as an alternative pharmacological therapy to insulin during pregnancy ${ }^{31}$ and its popularity as first-line treatment appears to be growing.

These changes in managing GDM may be welcome to women with gestational diabetes who are inconvenienced by injections and to those in areas where insulin may not be readily available or its cost and storage prohibitive. Such a change will certainly be greatly welcomed especially in the developing world.

\section{References}

1. Xiang AH, Ruth K, Trigo E, et al. Multiple metabolic defects during late pregnancy in women at high risk for type 2 diabetes. Diabetes 1999; 48: 848-54.

2. Moore TR et al. Diabetes Mellitus and Pregnancy. med/ 2349 at eMedicine. Version: Jan 27, 2005 update.

3. American Diabetes Association: Diagnosis and classification of diabetes mellitus. Diabetes Care 2006; 29(Suppl. 1): S43-S48.

4. Lawrence JM, Contreras R, Chen W, Sacks DA. Trends in the prevalence of preexisting diabetes and gestational diabetes mellitus among a racially/ethnically diverse population of pregnant women, 1999-2005. Diabetes Care 2008; 31: 899-904.

5. de Valk HW, van Nieuwaal NH, Visser GH. Pregnancy outcome in type 2 diabetes mellitus: a retrospective analysis from the Netherlands. Rev Diabet Stud 2006; 3(3): 134-42.

6. Dunne F, Brydon P, Smith K, Gee H. Pregnancy in women with type 2 diabetes: 12 years outcome data 1990-2002. Diabet Med 2003; 20(9): 734-8.

7. Barclay L. Gestational diabetes tends to recur in subsequent pregnancies. Published online July 12, 2010, Am J Obstet Gynecol.

8. Moore TR et al. Diabetes Mellitus and Pregnancy, Version: Jun 1, 2010 update eMedicine.

9. American Diabetes Association. Diagnosis and classification of diabetes mellitus. Diabetes Care 2006; 29(Suppl. 1): S43-S48.

10. Definition and Diagnosis of Diabetes Mellitus and Intermediate Hyperglycaemia. WHO Library 2006, World Health Organization.

11. Metzger BE, Lowe LP, Dyer AR, Trimble ER, Chaovarindr U, Coustan DR, Hadden DR, McCance DR, Hod M, McIntyre HD, Oats JJ, Persson B, Rogers MS, Sacks DA. Hyperglycaemia and adverse pregnancy outcomes. N Engl J Med 2008; 358: 1991-2002.

12. International Association of Diabetes and Pregnancy Study Groups Recommendations on the Diagnosis and Classification of Hyperglycaemia in Pregnancy. Diabetes Care 2010; 33: 676-83. 
13. Ratner RE, Christophi CA, Metzger BE, et al. Prevention of diabetes in women with a history of gestational diabetes: effects of metformin and lifestyle interventions. J Clin Endocrinol Metab 2008; 93: 4774-9.

14. Handelsman, Yehuda. A doctor's diagnosis: prediabetes. Power of Prevention 2009; 1.

15. Briggs GG, Freeman RK, Yaffe SJ. Drugs in pregnancy and lactation. 7th ed. Philadelphia: Lippincott Williams \& Wilkins, 2005: 1316, 1438.

16. Charles B, Norris R, Xiao X, Hague W. Population pharmacokinetics of metformin in late pregnancy. Ther Drug Monit 2006; 28: 67-72.

17. Langer O. Oral Antidiabetic Drugs in Pregnancy: The Other Alternative, Diabetes Spectrum (2010). American Diabetes Association.

18. Briggs GG, Freeman RK, Yaffe SJ. Drugs in pregnancy and lactation. 7th ed. Philadelphia: Lippincott Williams \& Wilkins, 2005: 1316, 1438.

19. Elliot BD, Langer O, Schenker S, et al. Comparative placental transfer of oral hypoglycaemic agents in humans: a model of human placental drug transfer. Am J Obstet Gynecol 1994; 171: 653-60.

20. Langer O, Conway DL, Berkus MD, et al. A comparison of glyburide and insulin in women with gestational diabetes mellitus. N Engl J Med 2000; 343: 1134-8.

21. Kraemer J, Klein J, Lubetsky A, Koren G. Perfusion studies of glyburide transfer across the human placenta: implications for fetal safety. Am J Obstet Gynecol 2006; 195: 270-4. Epub 30 Mar 2006

22. Shepard TH. Catalog of Teratogenic Agents. 8th ed. Baltimore, MD: Johns Hopkins University Press, 1995: 202.

23. Briggs GG, Freeman RK, YaffeSJ. Drugs in Pregnancy and Lactation. 7th ed. Philadelphia: Lippincott Williams \& Wilkins, 2005: 1316, 1438.

24. Langer O, Conway DL, Berkus MD, et al. A comparison of glyburide and insulin in women with gestational diabetes mellitus. N Engl J Med 2000; 343: 1134-8.

25. Kahn BF, Davies JK, Lynch AM, Reynolds RM, Barbour LA. Predictors of glyburide failure in the treatment of gestational diabetes. Obstet Gynecol 2006; 107: 1303-9.

26. Charles B, Norris R, Xiao X, Hague W. Population pharmacokinetics of metformin in late pregnancy. Ther Drug Monit 2006; 28: 67-72.

27. Glueck CJ, Wang P, Goldenberg N, Sieve-Smith L. Pregnancy outcomes among women with polycystic ovary syndrome treated with metformin. Hum Reprod 2002; 17: 2858-64.

28. Glueck CJ, Godenberg N, Pranikoff J, et al. Height, weight and motor-social development during the first 18 months of life in 126 infants born to 109 mothers with polycystic ovary syndrome who conceived on and continued metformin through pregnancy. Hum Reprod 2004; 19: 1323-30.

29. Gutzin SJ, Kozer E, Magee LA, Feig DS, Koren G. The safety of oral hypoglycemic agents in the first trimester of pregnancy: a meta-analysis. Can J Clin Pharmacol 2003; 10: 179-83.
30. Bertini AM, Silva JC, Taborda W, et al. Perinatal outcomes and the use of oral hypoglycemic agents. J Perinat Med 2005; 33: 519-23.

31. Metzger BE, Buchanan TA, Coustan DR, de Leiva A, Dunger DB. Summary and Recommendations of the Fifth International Workshop-Conference on Gestational Diabetes Mellitus. Diabetes Care 2007; 30: S251-S260.

32. Hieronimus S, Cupelli C, Bongain A, Durand-Reville M, Berthier F, Fenichel P. Pregnancy in type 1 diabetes: insulin pump versus intensified conventional therapy. Gynecol Obstet Fertil 2005; 33(6): 389-94.

33. Lapolla A, Dalfra MG, Masin M, Bruttomesso D, Piva I, Crepaldi C, et al. Analysis of outcome of pregnancy in type 1 diabetics treated with insulin pump or conventional insulin therapy. Acta Diabetol 2003; 40(3): 143-9.

34. Bernstein IM, Catalano PM. Influence of fetal fat on the ultrasound estimation of fetal weight in diabetic mothers. Obstet Gynecol 1992; 79(4): 561-3.

35. Lewis RB, Levkoff S, Stuebe A, et al. Gestational diabetes mellitus: postpartum opportunities for the diagnosis and prevention of type 2 diabetes mellitus. Nat Clin Pract Endocrinol Metab 2008; 4(10): 552-8.

36. Taeusch HW Jr, Wong YL, Torday JS, Epstein MF. Maternal glucocorticoid treatment and reduction of risk from respiratory distress syndrome. J Reprod Med 1979; 23(5): 252-6.

37. Banerjee S, Ghosh US, Banerjee D. Effect of tight glycaemic control on fetal complications in diabetic pregnancies. J Assoc Physicians India 2004; 52: 109-13.

38 Feig DS, Briggs GG, Kraemer JM, et al. Transfer of glyburide and glipizide into breast milk. Diabetes Care 2005; 28: 1851-5.

39. Ito S. Drug therapy for breast-feeding women. $N$ Engl J Med 2000; 343: 118-26.

40. Briggs GG, Ambrose PJ, Nageotte MP, et al. Excretion of metformin into breast milk and the effect on nursing infants. Obstet Gynecol 2005; 105: 1437-41.

41. Glueck CJ, Salehi M, Seve L, Wang P. Growth, motor and social development in breast- and formula-fed infants of metformin-treated women with polycystic ovary syndrome. J Pediatr 2006; 148: 628-32.

42. Bellamy L, Casas JP, Hingorani A, et al. Type 2 diabetes mellitus after gestational diabetes: a systematic review and meta-analysis. Lancet 2009; 373: 1773-9.

43. Volpe L, Cuccuru I, Lencioni C, et al. Early subclinical atherosclerosis in women with previous gestational diabetes mellitus. Diabetes Care 2008; 31: E32.

44. Di Cianni G, Ghio A, Resi V, Volpe L. Gestational diabetes mellitus: an opportunity to prevent type 2 diabetes and cardiovascular disease in young women. Women's Health 2010; 6(1): 97-105.

45. Shah BR, Retnakaran R, Booth G. Increased risk of cardiovascular disease in young women following gestational diabetes mellitus. Diabetes Care 2008; 31: 1668-9.

46. American Diabetes Association: Position Statement. Diagnosis and classification of diabetes mellitus. Diabetes Care 2007; 30(Suppl. 1): S4-S47. 
47. Catalano P. Management of obesity in pregnancy. Obstet Gynecol 2007; 109: 419-33.

48. Catalano PM, Thomas AJ, Avallone DA, Amini SB. Anthropometric estimation of neonatal body composition. Am J Obstet Gynecol 1995, 173: 1176-81.

49. McKinney PA, Parslow R, Gurney KA, Law GR, Bodansky HJ, Williams R. Perinatal and neonatal determinants of childhood type 1 diabetes. A case-control study in Yorkshire, U.K. Diabetes Care 1999; 22(6): 928-32.

50. Plagemann A. Perinatal programming and functional teratogenesis: impact on body weight regulation and obesity. Physiol Behav 2005; 86(5): 661-8.

51. Eriksson JG, Forsen TJ, Osmond C, Barker DJ. Pathways of infant and childhood growth that lead to type 2 diabetes. Diabetes Care 2003; 26(11): 3006-10.

52. International Association of Diabetes and Pregnancy Study Groups Recommendations on the Diagnosis and Classification of Hyperglycemia in Pregnancy. Diabetes Care 2010; 33: 676-82. American Diabetes Association.

53. National Collaborating Centre for Women's and Children's Health. Diabetes in Pregnancy: Management of Diabetes and Its Complications from Preconception to the Postnatal Period. (2008) RCOG Press, London, U.K.

54. Ben Haroush A, Yogev Y, Hod M. Epidemiology of gestational diabetes mellitus and its association with type 2 diabetes. Diabet Med 2004; 21: 103-13.

55. Lauenborg J, Grarup N, Damm P, et al. Common type 2 diabetes risk gene variants associate with gestational diabetes. J Clin Endocrinol Metab 2009; 94: 145-50 .

56. Cho YM, Kim TH, ChoiSH, et al. Type 2 diabetes-associated genetic variants discovered in the recent genome-wide association studies are related to gestational diabetes in the Korean population. Diabetologia 2009; 52: 253-61.

57. Buchanan TA, Xiang AH, Peters RK, et al. Preservation of pancreatic $\beta$-cell function and prevention of type 2 diabetes by pharmacological treatment of insulin resistance in high risk Hispanic women. Diabetes 2002; 51: 2796-803.

58. Coustan DR, Lowe LP, Metzger BE, Dyer AR. The Hyperglycemia and Adverse Pregnancy Outcome (HAPO) study: paving the way for new diagnostic criteria for gestational diabetes mellitus. Am J Obstet Gynecol 2010; 202: e1-e6. 